\title{
The Institutional Order of Liberalization
}

\author{
Amanda B. Edgell ${ }^{1 *}$ (D), Vanessa A. Boese ${ }^{2}$ (D), Seraphine F. Maerz ${ }^{2}$ (D) Patrik Lindenfors $^{3}$ \\ and Staffan I. Lindberg ${ }^{2}$ (D) \\ ${ }^{1}$ Department of Political Science, University of Alabama, Tuscaloosa, AL, USA, ${ }^{2} \mathrm{~V}$-Dem Institute, University of Gothenburg, \\ Gothenburg, Sweden and ${ }^{3}$ Institute for Futures Studies, Stockholm, Sweden \\ *Corresponding author. E-mail: abedgell@ua.edu
}

(Received 19 October 2020; revised 12 February 2021; accepted 7 April 2021; first published online 17 August 2021)

\begin{abstract}
When authoritarian regimes liberalize, are there observable patterns in the ordering of reforms, and are these patterns distinct for cases that transition to democracy? While the prevailing literature tends to focus on exogenous 'determinants' of democracy, this letter describes the endogenous dynamics of liberalization itself. Using pairwise domination analysis, it assesses the institutional order of reforms during 371 episodes of liberalization in autocracies between 1900 and 2019. Based on twenty-four indicators of democratic institutions and practices, our findings reveal (1) a clear pattern of reform during liberalization episodes, (2) with strong similarities across outcomes, but also that (3) reforms to the administration of elections tend to develop comparatively earlier in episodes of liberalization that produce a democratic transition.
\end{abstract}

Keywords: democratization; liberalization; episodes of regime transformation; sequential requisites; cultural evolution

When authoritarian regimes liberalize, are there observable patterns in the ordering of reforms, and are these patterns distinct for cases that transition to democracy? While scholars have sometimes puzzled over these endogenous dynamics of liberalization (for example, Dahl 1971; Dix 1994), the prevailing literature tends to focus on exogenous 'determinants', the regime context, the configurations of actors (for example, Huntington 1968; Linz and Stepan 1996; Lipset 1959; O’Donnell and Schmitter 1986; Przeworski 1991; Teorell 2010) or the relationship between democratization, state building, and conflict (for example, Carothers 2007a; Carothers 2007b; Mansfield and Snyder 1995; Mansfield and Snyder 2007). By contrast, this letter analyzes the process of liberalization itself.

Our goal is 'mere description', independent of any prior causal propositions (Gerring 2012); although, we do provide some tentative conclusions that may help to guide future causal-oriented research. We extend prior case-based and small-N findings by providing a general description of how the liberalization process unfolds, with comparisons across several possible outcomes regardless of the architects' intent. Using a sample of 371 episodes of liberalizing autocracy from 1900 to 2019 (Edgell et al. 2020), we employ pairwise domination analysis - a method adapted from evolutionary biology (Lindenfors et al. 2018; Lindenfors, Krusell and Lindberg 2019) - to describe the general order of reforms in twenty-four indicators of democratic institutions and practices from the Varieties of Democracy (V-Dem) data (Coppedge et al. 2020). This independent pursuit of description - while uncommon in our discipline - allows us to avoid potential biases in the quality and quantity of our descriptive inferences (Gerring 2012).

We make no claims about whether autocrats engaging in liberalization are genuinely prodemocratic or anti-democratic strategists. Liberalization is an inherently uncertain process with

(C) The Author(s), 2021. Published by Cambridge University Press. This is an Open Access article, distributed under the terms of the Creative Commons Attribution-NonCommercial-ShareAlike licence (http://creativecommons.org/licenses/by-nc-sa/4.0/), which permits non-commercial re-use, distribution, and reproduction in any medium, provided the same Creative Commons licence is included and the original work is properly cited. The written permission of Cambridge University Press must be obtained for commercial re-use. 
no guarantees for democracy (for example, Bratton and Van de Walle 1997; Linz and Stepan 1996; O’Donnell and Schmitter 1986). While autocracies often engage in institutional adaptation to avoid democratization (for example, Schedler 2002), such staged liberalization is also risky, sometimes producing 'democratization by mistake' (Treisman 2020). Likewise, liberalization may face resistance or backlash from conservative elements in society who benefit from maintaining the status quo. When this occurs, democracy may be pre-empted or liberalization reverted by anti-reform forces, even if pro-democratic actors are in charge of the process.

Our results reveal three novel insights about the liberalization process. First, autocracies tend to follow a common pattern in the ordering of reforms when undergoing liberalization. Secondly, there are remarkably few differences in this ordering for liberalization episodes that produce a democratic transition and those with non-democratic outcomes. Thirdly, when liberalization does yield a democratic transition (whether by design or by mistake), reforms to the administration of elections tend to occur earlier in the liberalization process. Taken together, our findings suggest that small endogenous changes to the reform process - especially those related to electoral integrity - could matter a great deal for the outcome of liberalization in autocracies.

\section{Data}

Our sample of liberalizing autocracies comes from the Episodes of Regime Transformation (ERT) dataset (Edgell et al. 2020). The ERT defines liberalization episodes as periods of substantial and sustained improvement in democratic institutions and practices, measured using the Electoral Democracy Index (EDI) from the V-Dem dataset (Coppedge et al. 2020). To be considered sustained and substantial, the default ERT data requires that the EDI increase by at least 0.01 in the initial year and by at least 0.10 (10 per cent of the total scale) throughout the episode. Episodes terminate due to prolonged (5-year) periods of stasis, any substantial one-year $(-0.03)$ or five-year $(-0.10)$ declines, or a reversal to closed autocracy on the Regimes of the World measure (Lührmann, Tannenberg and Lindberg 2018). Based on our knowledge of the cases, the ERT default episodes have strong face validity, and while these thresholds are admittedly arbitrary, all decisions about what constitutes liberalization on an interval scale of democracy would suffer from this criticism.

The ERT also codes the outcome of each episode, which allows us to explore heterogeneity in the sequence of reforms. A democratic transition occurs when a liberalizing autocracy becomes coded as a democracy, provided that elected officials assume office through a 'founding' election. Episodes that fail to meet this criterion are classified as one of three non-democratic outcomes. Reverted liberalization occurs when a liberalizing autocracy experiences a substantial drop in EDI scores or becomes reclassified as a closed autocracy. Stabilized electoral authoritarianism occurs when a liberalizing autocracy achieves electoral authoritarian status and has no change for 5 years. Finally, a pre-empted transition occurs when a liberalizing autocracy achieves electoral democracy but fails to hold elections before reverting back to authoritarianism.

Using these default criteria, the ERT contains 371 completed episodes of liberalization in autocracies from 1900 to 2019, of which 145 resulted in a democratic transition, 123 experienced reverted liberalization, eighty-seven stabilized as electoral authoritarian regimes and sixteen are pre-empted transitions. Another twelve episodes of liberalization are ongoing (that is, censored) in 2019 and are omitted from our analysis (see Appendix A1 for a complete list).

As the basis of the ERT, the EDI captures the institutional guarantees of democracy highlighted by Dahl (1971) using a set of fine-grained disaggregated indicators coded by country experts and aggregated using a Bayesian measurement model (see Coppedge et al. 2020; Pemstein et al. 2020; Teorell et al. 2019). We focus here on the twenty-four ordinal indicators included in the component indices for suffrage, clean elections, freedom of expression, alternative sources of information, and freedom of association (see Appendix A2). Given our interest in the temporal ordering of reforms, we omit the elected officials index from our analysis because it exhibits limited within-country variation in our sample. 


\section{Methods}

We employ pairwise domination analysis, a method of exploring the temporal relationship between ordinal variables adapted from evolutionary biology (Lindenfors et al. 2018; Sillén-Tullberg 1993; used in Mechkova, Lührmann and Lindberg 2019; Wang et al. 2017). This method involves comparing the ordinal levels of pairs of indicators to assess which are dominant within the overall system of indicators. We define domination to be present when an indicator's ordinal level is greater than another indicator for more than 50 per cent of the observations. In a dataset in which there is a general directional movement from lower to higher, such as the liberalization episodes used here, we can infer that a dominant indicator attained higher values earlier than the indicators it dominates.

Using the R package seqR (Krussell 2017), we compare the observed values of all unique pairs of the twenty-four selected ordinal indicators from the EDI. This produces a matrix of 276 unique pairwise comparisons. We then sum the number of other indicators an indicator dominates $(d)$ or is dominated by $(r)$, producing a domination table. To aid with interpretation, we develop a domination score based on the difference in these two values (score $=r-d$ ), with lower values indicating that the variable dominates many other variables and thus develops earlier in the liberalization process. While the possible range for the domination score in this analysis is -23 (completely dominant) to 23 (completely dominated), observed values range from -21 (suffrage in stabilized electoral authoritarian outcomes) to 22 (vote buying in pre-empted transition outcomes). To estimate similarities in these scores across different episode outcomes, we use simple bivariate linear regressions and their residuals.

This approach carries some important assumptions. First, we assume that 50 per cent is substantial enough to constitute domination. We base this threshold on two intuitions: (1) since we are looking for the most common path(s) of liberalization, we highlight those relationships that occur a majority of the time; and (2) empirically, the 50 per cent threshold establishes a clear pattern of dominance. For a given pair of ordinal indicators, $\mathrm{X}$ and $\mathrm{Y}$, when $\mathrm{X}>\mathrm{Y}$ more than 50 per cent of the time, it is rarely the case that $\mathrm{X}<\mathrm{Y}$ more than 20 per cent of the time because $\mathrm{X}=\mathrm{Y}$ is also commonly present. Our main conclusions are robust when we adjust the domination threshold to two-thirds of the observations (see Tables A10 and A11). Such a conservative threshold, however, implies a shift in focus to the most likely or even deterministic path(s) of liberalization and produces a rather sparse domination matrix (see Table A12).

Secondly, the method requires that the ordinal scale remains consistent between observations on the same indicator. The V-Dem data should largely conform to this assumption, given to the project's extensive work on addressing differential item functioning of expert ratings using a variety of tools (Marquardt et al. 2019; Marquardt and Pemstein 2018; Pemstein et al. 2020). In addition, because events can play out quickly in one country and slowly in another, we remove the year element and focus on state changes and their order. To achieve this, we combine all consecutive country-year observations when values of all twenty-four variables are constant into a single observed 'state'. This also resolves the problem that stable states could overwhelm changes in terms of numbers. We report comparable results using country-year data in Appendix (Tables A7, A8 and A9).

Thirdly, the ordinal scales between indicators should be comparable. An ordinal level on one indicator should correspond to the same level on all other indicators in the analysis (for example, ordinal level 1 should correspond to a 1 on everything else). At a minimum, this implies that the indicators should all have the same observable ranges and level of measurement. For this reason, we rescale three media variables (by $\mathrm{min} / \mathrm{max}$ ) and suffrage (by quintiles) into a similar $0-4$ ordinal scale for comparability. There is still a risk that some indicator scales do not correspond well. Thus, we cautiously interpret the raw values from the domination matrix. Instead, we report relative domination scores and their correlation between episode outcomes rather than absolute differences. These can be found in Appendix A3 and the replication data. 
By focusing solely on descriptive evidence about the ordering or sequence of reforms, our analysis does not account for intervening exogenous variables that could disrupt the liberalization process. Events like conflict, economic recession, natural disasters, and pandemics may alter the regime context, the available choices, and the calculus of incumbents. We do not seek to downplay or ignore the potential importance of these variables. Rather, we focus on the internal reforms process itself because this question has not received sufficient attention in the literature, particularly using large- $\mathrm{N}$ analyses. Nevertheless, we recognize that the results of our domination analyses may be at least partly driven by unobserved exogenous confounders. We leave this question for future research.

\section{Results}

Figure 1 plots the domination scores for each of the twenty-four indicators, comparing episodes with a democratic transition (horizontal axis) to those that had a non-democratic outcome (vertical axis). Indicators developing comparatively earlier and comparatively later for both outcomes appear in the lower left and upper right quadrants, respectively. The shaded region represents the estimated 99 per cent confidence interval from a bivariate linear regression between values for episodes with and without a democratic transition. The indicator for electoral management body (EMB) capacity, for example, is in the upper-right quadrant, meaning it develops rather late in cases that have experienced a democratic transition and even later for non-democratic outcomes. By contrast, the indicator for multiparty elections is in the lower-left quadrant, developing comparatively early for both cases with a democratic transition and non-democratic outcomes. More generally, this figure yields three novel insights about the institutional order of liberalization in autocracies.

First, the results reveal a remarkable consistency in the ordering of reforms during liberalization. Secondly, this ordering is surprisingly consistent regardless of the outcome (also evidenced in Table A3). The fitted linear regression shows a strong correlation between domination scores for democratic and non-democratic outcomes, with a coefficient $(b)$ of $0.94(p<0.001)$ and an adjusted $\mathrm{R}^{2}$ of 0.85 (see Model 1, Table A4). Institutions related to multiparty elections, political party development, and suffrage tend to come comparatively earlier (bottom left), whereas improvements in the quality of elections (vote buying, other irregularities, and EMB autonomy) and harassment of journalists tend to come later (top right) across all episodes. With an average residual of zero and a median of just -1.94 , most indicators are within close proximity to the regression line and well within the 99 per cent confidence interval. On a qualitative level, when we look to the upper-left and lower-right quadrants, we find that few indicators develop earlier for one outcome but later for the other.

Thirdly, we find that variables related to the administration of elections exhibit the greatest deviation, coming relatively earlier in autocracies that successfully democratized. In particular, and despite developing later across all episodes (upper-right quadrant), EMB capacity has the highest residual value $(e=12.13)$. This is driven by its high domination score in episodes with non-democratic outcomes, where it is dominated by fourteen other indicators and dominant over none. By contrast, in episodes with democratic outcomes, EMB capacity is dominated by only the five indicators that generally develop very early (suffrage, party bans, barriers to parties, opposition party autonomy, and multiparty elections and dominates three indicators that otherwise usually develop later (other voting irregularities, vote buying, and harassment of journalists). Other indicators for EMB autonomy, free and fair elections, and voter registry appear in the upper-left quadrant, coming earlier in episodes with a democratic transition but later in those with non-democratic outcomes. However, the magnitude of their residuals is smaller $(e=4.97$, 4.94, 4.94, respectively). Values are election specific for free and fair elections and voter registry; thus we are cautious about this result. Party bans and academic and cultural expression are the only indicators with a comparable negative residual ( $e=-5.03$ and -4.55 respectively), suggesting 


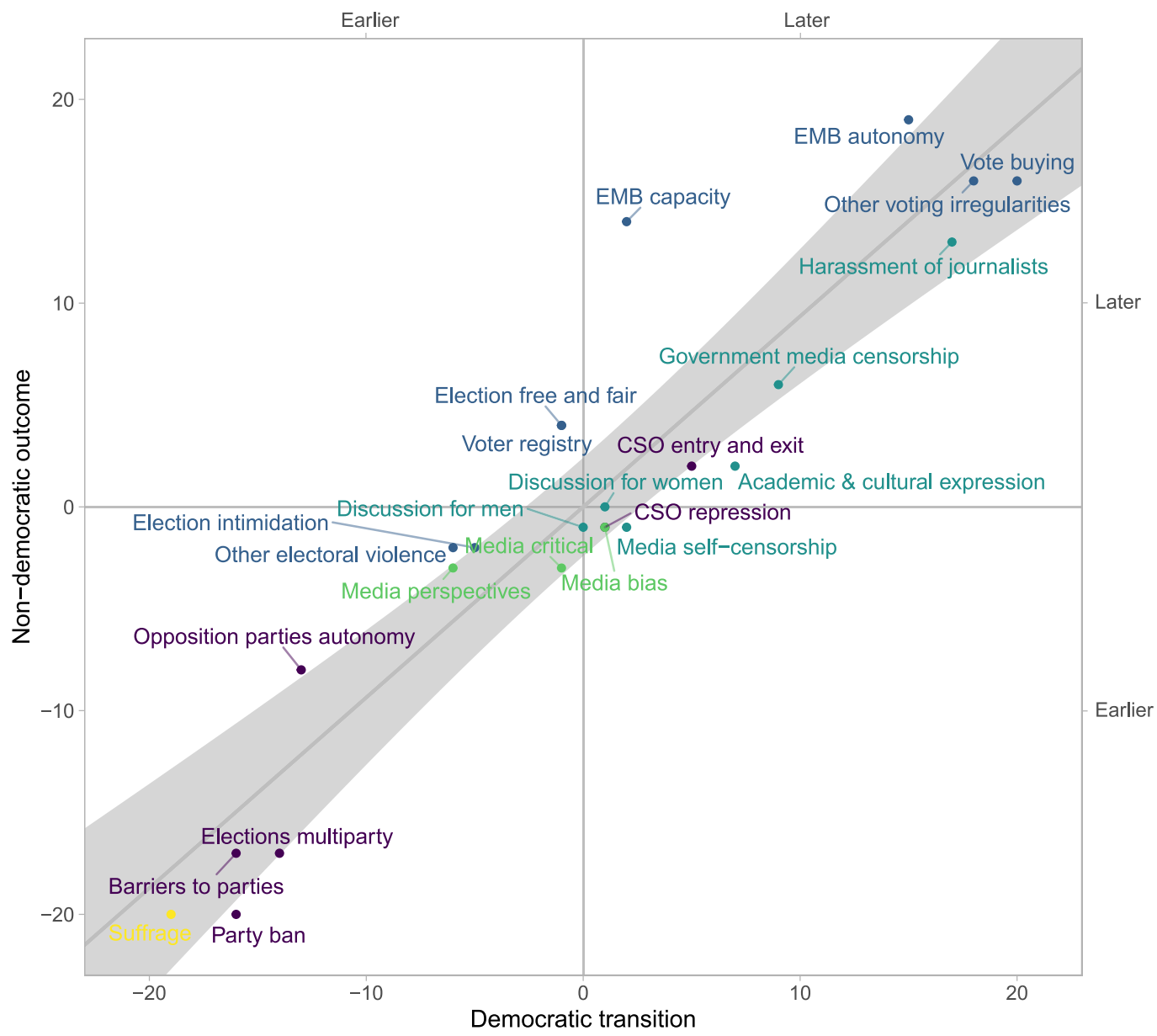

- Association Clean elections - Expression Information Suffrage

Figure 1. Pairwise domination scores by outcome for twenty-four indicators of democracy during episodes of liberalizing autocracy

Note: scores for the $\mathrm{x}$ - and $\mathrm{y}$-axis are reported in Table A3. The shaded area represents the 99 per cent confidence interval for linear fit between values for episodes with and without a democratic transition. EMB = electoral management body; CSO=civil society organization

that while liberalization in these areas generally comes early across all episodes, it may occur somewhat earlier in episodes with non-democratic outcomes.

We find that these strong similarities in the liberalization process persist across the three types of non-democratic outcomes once they are disaggregated (see Table A4 for models and Table A5 for residuals). As one might expect, pre-empted transitions, or those 'near misses' for democracy, are most similar to episodes with democratic outcomes $(b=1.01$, see Model 2). Meanwhile, episodes resulting in a stabilized electoral authoritarian regime exhibit the least similarity $(b=0.86$, see Model 3). Notably, while EMB capacity continues to have the highest residual for pre-empted transitions $(e=12.98)$ and reverted liberalizations $(e=16.04)$, it is much lower for episodes ending in electoral authoritarianism $(e=3.27)$. Harassment of journalists $(e=-8.69)$ has the largest residuals for electoral authoritarianism, suggesting that this area improves earlier compared to episodes with democratic outcomes. Here our goal is verbose language that can be removed for precision to take 
seriously the endogenous ordering of reforms during liberalization, to apply a novel technique for descriptive inference of this ordering, and to show that these are actually quite similar regardless of the outcome, yet where some particular aspects stand out as different. Those are prime candidates for further theorizing and empirical testing, which future research should undertake.

\section{Conclusion}

While scholars have long theorized about the endogenous process of political liberalization (Dahl 1971; Huntington 1968; O'Donnell and Schmitter 1986), the chronology of liberalizing reforms remains underexamined. Our findings provide evidence that liberalizing autocracies generally follow a similar sequence of steps, tending to prioritize suffrage and political parties early on and elements related to clean electoral practices (such as reduced vote buying and other irregularities, alongside harassment of journalists) in the later stages. We also find that this overall sequence of reforms is fairly consistent across liberalization episodes, regardless of the outcome. Yet some key differences emerge. For example, earlier investments in EMB capacity and autonomy are associated with democratic outcomes.

Thus, our descriptive analysis presents two plausible inferences. First, the strong similarities in the patterns of reforms could suggest that exogenous factors matter more than institutional ordering when explaining the outcomes of liberalization. If so, the results support the prevailing exogenous 'determinants' trend in the large-N literature. Secondly, and alternatively, our findings could mean that very small changes in the ordering of reforms have substantive effects on the propensity for democratization. If the latter holds, earlier reforms to electoral management bodies, voter registries, and free and fair elections may provide important insights into the trajectories of liberalizing autocracies.

Notably, these institutions are also available for 'treatment' by interventions. While our approach remains descriptive, future research could help to reveal whether this difference is causal and whether it holds up to models accounting for exogenous forces. In other words: Do small variations in the ordering have larger downstream consequences for democratization, akin to consequences of tiny differences in evolutionary processes? Do such differences have any causal significance?

Supplementary material. Online appendices are available at https://doi.org/10.1017/S000712342100020X.

Data availability statement. All replication materials for this article are available in Havard Dataverse at: https://doi.org/10. 7910/DVN/POXKUY.

Acknowledgements. We appreciate valuable feedback from Matthew C. Wilson, the V-Dem Institute researcher group, and three anonymous reviewers.

Author contribution. Amanda B. Edgell took the lead on the design of this project, conducted the data analysis and made substantial contributions to the written text. Vanessa A. Boese and Seraphine F. Maerz took the lead on drafting the text and assisted with the data analysis and interpretation. Patrik Lindenfors and Staffan I. Lindberg originally conceptualized this letter. Lindenfors developed the domination analysis methodology and contributed to the data analysis process. Lindberg played an important role in the design, assisted with the interpretation and made substantial contributions to the written text.

Financial support. This research project was supported by the Knut and Alice Wallenberg Foundation to Wallenberg Academy Fellow Staffan I. Lindberg, Grant 2018.0144; by European Research Council, Grant 724191, PI: Staffan I. Lindberg, V-Dem Institute, University of Gothenburg, Sweden; Marianne and Marcus Wallenberg Foundation to Patrik Lindenfors, Grant 2017.0049; as well as by internal grants from the Vice- Chancellor's office, the Dean of the College of Social Sciences, and the Department of Political Science at University of Gothenburg.

Conflicts of interest. None.

\section{References}

Bratton M and Van de Walle N (1997) Democratic Experiments in Africa: Regime Transitions in Comparative Perspective. Cambridge: Cambridge University Press. 
Carothers T (2007a) Exchange: misunderstanding gradualism. Journal of Democracy 18(3), 18-22.

Carothers T (2007b) How democracies emerge: the 'sequencing' fallacy. Journal of Democracy 18(1), 12-27.

Coppedge M et al. (2020) V-Dem country-year dataset v10. Varieties of Democracy (V-Dem) Project. Available from https:// doi.org/10.23696/vdemds20.

Dahl RA (1971) Polyarchy: Participation and Opposition. New Haven, CT: Yale University Press.

Dix RH (1994) History and democracy revisited. Comparative Politics 27(1), 91-105.

Edgell AB et al. (2020) Episodes of Regime Transformation (ERT) dataset, v1.0. Available from https:/github.com/ vdeminstitute/vdemdata.

Edgell AB et al. (2021) Replication data for: The institutional order of liberalization. https://doi.org/10.7910/DVN/POXKUY, Harvard Dataverse, V1, UNF:6:5GRTUEi4aOV6SFr + ulksvQ $==$ [fileUNF].

Gerring J (2012) Mere description. British Journal of Political Science 42(4), 721-746.

Huntington SP (1968) Political Order in Changing Societies. New Haven, CT: Yale University Press.

Krussell J (2017) SeqR: ordinal sequence analysis, version 0.1.0. Available from https://github.com/jsks/seqR.

Lindenfors $\mathbf{P}$ et al. (2018) Investigating sequences in ordinal data: a new approach with adapted evolutionary models. Political Science Research and Methods 6(3), 449-466.

Lindenfors P, Krusell J and Lindberg SI (2019) Sequential requisites analysis: a new method for analyzing sequential relationships in ordinal data. Social Science Quarterly 100(3), 838-856.

Linz JJ and Stepan A (1996) Problems of Democratic Transition and Consolidation: Southern Europe, South America, and Post-Communist Europe. Baltimore, MD: Johns Hopkins University Press.

Lipset SM (1959) Some social requisites of democracy: economic development and political legitimacy. American Political Science Review 53(1), 69-105.

Lührmann A, Tannenberg M and Lindberg SI (2018) Regimes of the World (RoW): opening new avenues for the comparative study of political regimes. Politics \& Governance 6(1), 60-77.

Mansfield ED and Snyder J (1995) Democratization and the danger of war. International Security 20(1), 5-38.

Mansfield ED and Snyder J (2007) Exchange: the sequencing 'fallacy'. Journal of Democracy 18(3), 5-9.

Marquardt KL et al. (2019) What makes experts reliable? Expert reliability and the estimation of latent traits. Research of Politics 6(4), 2053168019879561.

Marquardt KL and Pemstein D (2018) IRT models for expert-coded panel data. Political Analysis 26(4), 431-456.

Mechkova V, Lührmann A and Lindberg SI (2019) The accountability sequence: from de-jure to de-facto constraints on governments. Studies in Comparative International Development 54(1), 40-70.

O'Donnell G and Schmitter PC (1986) Transitions from Authoritarian Rule: Tentative Conclusions about Uncertain Democracies. Baltimore, MD: Johns Hopkins University Press.

Pemstein D et al. (2020) The V-Dem measurement model: latent variable analysis for cross-national and cross-temporal expert-coded data. Varieties of Democracy Institute Working Paper 21 (5th ed.).

Przeworski A (1991) Democracy and the Market: Political and Economic Reforms in Eastern Europe and Latin America. Cambridge: Cambridge University Press.

Schedler A (2002) The menu of manipulation. Journal of Democracy 13(2), 36-50.

Sillén-Tullberg B (1993) The effect of biased inclusion of taxa on the correlation between discrete characters in phylogenetic trees. Evolution 6, 1182-1191.

Teorell J (2010) Determinants of Democratization: Explaining Regime Change in the World, 1972-2006. Cambridge: Cambridge University Press.

Teorell J et al. (2019) Measuring polyarchy across the globe, 1900-2017. Studies in Comparative International Development 54(1), 71-95.

Treisman D (2020) Democracy by mistake: how the errors of autocrats trigger transitions to freer government. American Political Science Review 114(3), 792-810.

Wang Y-T et al. (2017) Women's rights in democratic transitions: a global sequence analysis, 1900-2012. European Journal of Political Research 56(4), 735-756.

Cite this article: Edgell AB, Boese VA, Maerz SF, Lindenfors P, Lindberg SI (2022). The Institutional Order of Liberalization. British Journal of Political Science 52, 1465-1471. https://doi.org/10.1017/S000712342100020X 